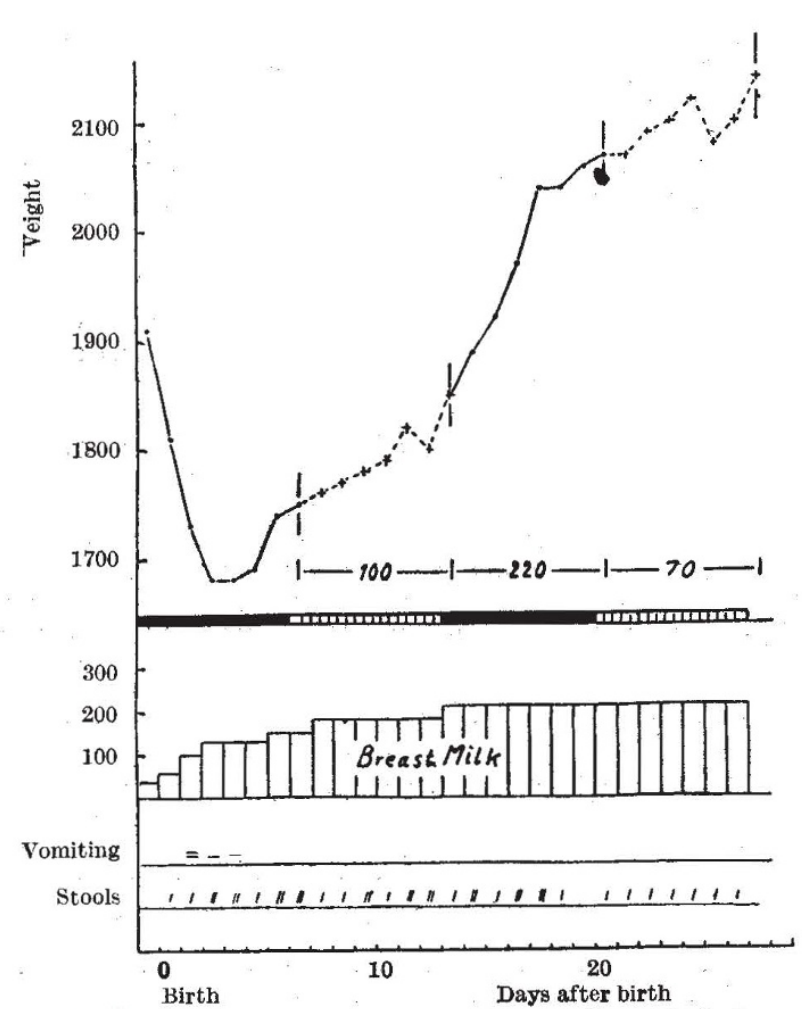

FIG. 2. GIRL, BORN 1 MONTH BEFORR TRRM. BIRTH-WRIGHT, $1,960 \mathrm{GM}$.

In the weight curve, $+-{ }_{+}+-$indicates periods in which the infant received, in addition to the breast milk, undigested casein plus glucose plus salt mixture, and the 'ladder' below indicates the amount of this mixture (10 c.c. daily per $\mathrm{gm}$. body weight) which was fed.

was 10 c.c. of 'Aminosol'-glucose per kgm. of body weight. This amount was almost invariably well tolerated by even the smallest of the infants without any complications arising in the form of vomiting or digestive disturbances. With some infants half this dose was sufficient to produce a good gain in weight. The cases cited below are appended to illustrate the results.

Some data are presented in Fig. 1.

It cannot be asserted with certainty that the greater gain in weight occurring while the infant was receiving the additional feeds of 'Aminosol'-glucose was due exclusively to the amino-acid mixture, although from the physiological point of view it would seem obvious that this was the cause. One objection that may be raised.against this assumption is that the infant was receiving more calories during these periods and that the gain in weight was due to this fact. In order to clear up this point, a series of tests was made in which the effect of feedings of 'Aminosol'-glucose was compared with the result obtained from a mixture containing undigested casein, glucose, and mineral salts of the same strengths and in the same proportions as in 'Aminosol'glucose. The only difference in the two foods was that the amino-acid mixture was exchanged for undigested casein. Some results are shown in Fig. 2.

In all the tests in which the effect of the aminoacid mixture was compared with that of undigested casein, the gain in weight was much greater in the periods during which the amino-acid mixture was being fed. Thus the amount of calories we supplied through this additional food cannot in itself have been the reason why the infant put on so much extra weight. The cause is undoubtedly to be sought in the feeding of amino-acids. To judge from certain cases, it would almost seem as if the amino-acids are used quantitatively for protein synthesis, since the daily weight increase was approximately equal to the gain in weight which would be obtained through protein synthesis and binding of the corresponding amount of water.

${ }^{1}$ Shohl, A. T., Butier, A. M., Blackfan, K. D., and MacLachlan, E., J. Pediat., 15, 469 (1939).

2 Hill, L. W., J. Amer. Med. A8soc., 116, 2135 (1941)

\section{TEACHING OF PLANT GENETICS}

$\mathrm{O}^{\mathrm{N}}$ February 20, 1943, Dr. W. Burns, agricultural commissioner with the Government of India, delivered his presidential address to the Indian Society of Genetics and Plant Breeding on the subject of the teaching of plant genetics in India (Indian $J$. Genetics and Plant Breeding, 3, 1 ; 1943). His comprehensive survey and discussion of this question, based as they are on a wide experience of the application of genetics to Indian agriculture, call for consideration in some detail.

Dr. Burns thinks that the rudiments of genetics should form part of the liberal education of those who proceed beyond the secondary school, because our behaviour and reaction to many situations must be profoundly affected by our understanding of the part played by heredity. A general raising of the level of biological teaching in schools is one of the essential prerequisites of teaching genetics and would enable "the future citizen, administrator or specialist to handle problems dealing with living things, including man, less ignorantly". The specialist in biology, medicine or agriculture requires, of course, a wider knowledge of genetics, since there are few biological problems the genetical aspects of which can be safely neglected. The plant breeder must have available to him all the resources of genetical science.

Genetical teaching is bound to be affected by the rapid and, in some ways, uneven growth of the subject. The necessary perspective could be introduced by a short historical survey. Elementary courses in genetics should aim at making clear the basic concept of the genotype and the chromosome theory of heredity, and should be preceded by a botany course and an introduction to biometrical mathematics. Instruction in eytology should be included in the botany course, and should involve the making of simple preparations of dividing nuclei. Practical work in elementary genetics itself would of necessity be largely on prepared material in the laboratory.

The biological specialist requires an additional preliminary course in floral biology to acquaint him with the structure and action of different floral mechanisms, the operation of incompatibility, and the methods used in making controlled pollination by artificial means. The genetical course itself should begin with a biometrical study of naturally occurring variation, proceeding via the distinction between heritable and non-heritable variation to Mendelism and chromosome theory. The student should count 
segregating families and so be led to an understanding of sampling variation and tests of goodness of fit. Finally, the bearings of genetics on evolutionary theory and taxonomy should be made clear, with special reference to complex, or polygenic, inheritance. This would require that the teachers themselves should have studied the problem carefully, and should have "some form of belief and not merely a chaos" in their minds. Dr. Burns also recorded a protest against the tyranny of the herbarium method and a plea for a fuller studv of living plants in taxonomy.

With reference to the plant preeder, it is clear that he should receive a fuller mathematical training than the other classes of student, for otherwise he must acquire it "painfully, perhaps self-taught" at a later and less convenient stage. He should also have a more comprehensive course in genetics, though it could be modelled on the lines sketched earlier. He would require an introduction to the modern theory and practice of field experiments, with practical work involving responsibility for an actual trial. The part to be played by statistics was discussed in relation to the danger of an undue adherence to statistical methods leading to a neglect of the living plants. The solution is essentially that of training the breeder to rely primarily on observations of, and familiarity with, his crop; and to show him how his observations can be amplified and checked by statistical analyses.

Dr. Burns concluded with a survey of the present position of genetics teaching in India, which he found far from satisfactory. He advocated the giving of preliminary instruction in the universities and of advanced courses in agricultural institutes. Above all, if this genetical teaching is to be fruitful the students must be led to grow-plants and study them as living things. The provision of facilities for this should not be too great a tax on the resources of educational establishments ; but there is a need for a small hand-book of practical genetics using the plants, chillies, rice, etc., with which Indians are familiar.

This discussion of teaching in plant genetics is noteworthy in a variety of ways, but especially perhaps for its insistence on the following points :

(1) The argument for the wider teaching and appreciation of general biology and the genetical point of view.

(2) The introduction of perspective into genetics by the approach through observable variation in Nature and the linking of genetics to evolutionary theory and taxonomy.

(3) The need for preliminary courses in floral biology and mathematics, and the introduction of modern statistical methods into the teaching.

(4) The emphasis on relating genetics teaching to the living organism as a corrective to over-formalization.

It must be remembered that Dr. Burns was discussing plant genetics in India, and so his various points may not apply with equal emphasis to all genetics in all countries. His separation of cytology from geneties and its inclusion in the botany course, for example, will not be desirable ev́erywhere. Nevertheless, his conclusions and proposals merit the careful study of all who are concerned with genetics and its teaching. His remarks are indeed especially timely in view of the expansion of genetics and genetical teaching which must now be contemplated in Great Britain.

\section{GEOLOGISTS IN THE POST-WAR PERIOD}

$T$ HE total number of British geologists wholly ongaged in a professional capacity in pre-war years was probably less than six hundred, nearly one quarter of whom were occupied in the teaching of the science, principally in the universities. To some extent this high proportion of geologists engaged in academic spheres is due to the fact that large classes of technical students in mining, metallurgy, civil engineering, and agriculture require tuition in geology as a part of their professional training.

The Geological Society of London has recently given evidence on the post-war recruitment of professional geologists, to the Inter-Departmental Committee on Further Education and Training, under the chairmanship of Lord Hankey. After expressing the hope that geology should be introduced into the schools as a fundamental study in general science courses, the Society stressed the important part that geologists play in the discovery and development of mining fields and oilfields, and in many branches of civil engineering.

In spite of the importance of geological work, the normal pre-war number of fully-trained geologists graduating each year from British universities is only about thirty. Although there have been wide fluctuations in the demand for mining and oil geologists, as a result of trade cycles, the supply of suitable men has usually been inadequate. It is probable that there will be a still greater dearth of British-trained geologists in the immediate post-war period, owing to the requirements of industry, Government Geological Surveys, and university teaching staffs. Within two years after the cessation of hostilities, it seems likely that considerably more than a hundred recruits will be called for to fill gaps and augment the ranks of professional geologists. It is certain that as soon as the War ends, there will be a demand for more men on the Geological Survey of Great Britain and the Colonial Geological Surveys.

Owing to impending retirements and proposed expansion of staff, there will be an immediate call for not less than ten men on the Geological Survey of Great Britain, with further recruitment in succeeding years. Representations have been made to the Secretary of State for the Colonies by the Geological Society and the Institution of Mining and Metallurgy, and it is confidently anticipated that many additional geologists will be enrolled for the staffs of the Colonial Geological Surveys. Not only is there a need for pressing on with routine geological mapping in the Colonies, but there is also great scope for more work to be done in connexion with the development of mineral resources, water supply, public works (dams, reservoirs, harbours, roads, etc.), and soil conservation. It has also been pointed out that several heads of university geological departments must soon be retiring under the age limit, and a number of junior posts in these departments will also be vacant. Within recent years new avenues of employment for geologists in industry have been opening up.

There are ample opportunities for trained geologists in the British oil companies, which face immediate post-war projects necessitating the employment of geological staffs larger than heretofore. Oilfields in Burma and elsewhere in the Far East will have to be re-opened, and studies must be made of the effect of Japanese operations, and of the best means of re- 